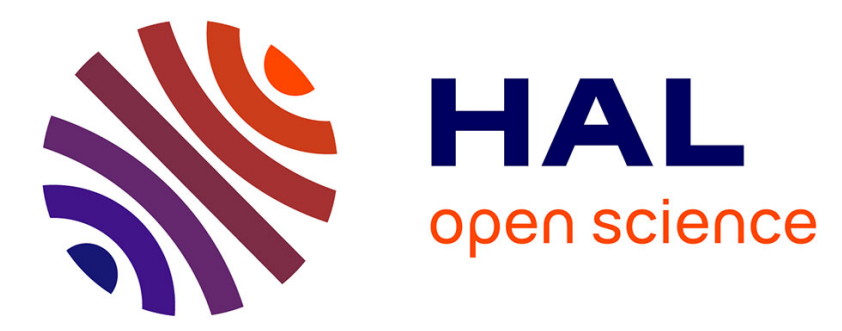

\title{
Long-period earthquake ground displacements recorded on Guadeloupe (French Antilles)
}

\author{
Philippe Jousset, John Douglas
}

\section{To cite this version:}

Philippe Jousset, John Douglas. Long-period earthquake ground displacements recorded on Guadeloupe (French Antilles). Earthquake Engineering and Structural Dynamics, 2007, 36 (7), pp.949-963. 10.1002/eqe.666 . hal-00557610

\section{HAL Id: hal-00557610 https: / hal-brgm.archives-ouvertes.fr/hal-00557610}

Submitted on 19 Jan 2011

HAL is a multi-disciplinary open access archive for the deposit and dissemination of scientific research documents, whether they are published or not. The documents may come from teaching and research institutions in France or abroad, or from public or private research centers.
L'archive ouverte pluridisciplinaire HAL, est destinée au dépôt et à la diffusion de documents scientifiques de niveau recherche, publiés ou non, émanant des établissements d'enseignement et de recherche français ou étrangers, des laboratoires publics ou privés. 


\title{
Long-period earthquake ground displacements recorded on Guadeloupe (French Antilles)
}

\author{
P. Jousset*\& J. Douglas \\ BRGM - ARN, 3 avenue C. Guillemin, BP 36009, 45060 Orléans Cedex 2, France.
}

\section{SUMMARY}

Displacement time-histories derived from accelerograms of three recent earthquakes in western North America (Hector Mine, $M_{w} 7.1$; Denali, $M_{w} 7.9$; and San Simeon, $M_{w} 6.5$ ) have been shown to feature large long-period $(\sim 10 \mathrm{~s})$ ground motion cycles. Such long-period displacements cause a localized peak within the displacement response spectrum that is currently not considered within any earthquake engineering design spectra. These displacement pulses have also been shown to be persistent and to feature on time-histories from widely-separated stations $(\sim 20 \mathrm{~km})$.

Broadband and accelerometric data from the Les Saintes earthquake sequence of 2004-2006 $\left(4.9 \leq M_{w} \leq 5.3\right)$ recorded on Guadeloupe (French Antilles) are shown in this article to feature similar long-period motions. The broadband data is used to independently corroborate the displacement timehistories derived through high-pass filtering and double integration of accelerometric data. It is shown that high-quality broadband data is suitable for this purpose. The long-period motions observed cause a localized peak in displacement response spectra at periods between 5 to $10 \mathrm{~s}$. It is suggested here

\footnotetext{
${ }^{*}$ Correspondence to: BRGM - ARN, 3 avenue C. Guillemin, BP 36009, 45060 Orléans Cedex 2, France.
} 
that the cause of these large-amplitude long-period motions are specific source mechanisms, which may possibly involve the presence of fluids within the source.

The form of the displacement response spectra from these time-histories is significantly different from the spectral shape specified in recent seismic design codes since the peak in the spectra is at a much greater period than expected. This leads to an underestimation of spectral displacements for periods between about 5 and $10 \mathrm{~s}$. Therefore if these observed long-period cycles are a common feature of earthquake ground motions the standard form of displacement design spectra may need to be reconsidered.

Copyright (c) 2002 John Wiley \& Sons, Ltd.

KEY WORDS: strong-motion data; ground displacements; displacement spectra; French Antilles; source fluids

\section{Introduction}

Obtaining reliable long-period ( $>1 \mathrm{~s}$ ) ground-motion measurements of earthquakes is difficult due to recording and processing noise. The advent of high-quality digital accelerometers with high (24 bit) resolution has led to a significant reduction in the level of noise in accelerograms and consequently a larger usable bandwidth [e.g. 10].

Using records from such digital instruments Boore et al. [12] for the 1999 Hector Mine earthquake $\left(M_{w} 7.1\right)$, Boore [9] for the 2002 Denali earthquake $\left(M_{w} 7.9\right)$ and Wang et al. [35] for the 2003 San Simeon earthquake $\left(M_{w} 6.5\right)$ discovered long-period $(\sim 10 \mathrm{~s})$ pulses in the processed displacement traces that had not been observed in previous earthquakes (possibly because earlier earthquakes were mainly recorded by analogue accelerographs and hence such long-period features could not be resolved). These pulses contribute to a conspicuous localized 
peak in the displacement response spectra of the records that could be important for the seismic design of long-period structures, such as large bridges, tall buildings and base-isolated structures.

In this article similar long-period displacement pulses are shown to feature on records from three predominately normal-faulting aftershocks of the 2004 Les Saintes earthquake $\left(M_{w} 6.3\right)[$ e.g. 6] near Guadeloupe (French Antilles). Processed displacement records from almost collocated accelerometers and broadband seismometers are compared to confirm that these displacement pulses are real and not just a consequence of recording noise. Interestingly, these aftershocks have much lower magnitudes $\left(4.9 \leq M_{w} \leq 5.3\right)$ than those in which such long-period pulses have been observed in the past, suggesting that these motions can occur during moderate-size earthquakes. Such long-period displacements mean that the displacement spectra of these records have peaks at periods between 5 and $10 \mathrm{~s}$, which is surprising due to the relatively small size of the earthquakes.

These observations are important from both an engineering and a seismological perspective. From the engineering point of view, the purpose of this article is to examine recently proposed design displacement response spectra in the light of these records. The importance of examining the shape of the displacement spectra proposed in design codes has recently been highlighted by Bommer \& Pinho [7]. In a seismological context, a possible generation mechanism (fluids within the source) for these large-amplitude long-period motions is suggested based on previous observations of similar motions. 
2. Use of broadband data for strong-motion seismology

Data from standard broadband seismometers have not often been used in strong-motion seismology partly because the higher sensitivity of such instruments means that ground motions from close to the source of moderate and large earthquakes are clipped [e.g. 19]. Some studies, such as Dahle et al. [18], use records from seismometers to supplement the limited accelerometric data available from their regions of interest (often stable continental regions) and from hard rock sites. Similarly Frisenda et al. [24] and Bragato \& Slejko [13] combine seismometric and accelerometric data in order to create a large set of records for studying the scaling, with magnitude and distance, of ground motions from small and moderate earthquakes in north-west Italy and in the eastern Alps, respectively. Note that the interest in these studies are accelerations obtained from seismograms whereas here the interest is displacements.

Zahradník [38] shows that the noise levels in seismograms are generally lower and have different characteristics than those in accelerograms. These lower noise levels mean that the usable bandwidth of records from seismometers should be greater than those from accelerometers and hence more reliable displacements can be obtained. A recent study that exploits these lower noise levels is that by $\mathrm{Yu} \& \mathrm{Hu}$ [37] who compare records from collocated accelerometers and broadband seismometers of the TriNet network in southern California. They find that reliable ground motions can be obtained up to a period of $20 \mathrm{~s}$, which allows them to derive ground-motion estimation equations for long-period acceleration response spectral ordinates.

A network of five stations with Güralp CMG40-T broadband seismometers (flat response between 0.016 and $100 \mathrm{~Hz}$ ) was recently installed at Bouillante on the west coast of Basse-Terre (Guadeloupe, France) for a geothermal project [29]. These stations are close 
together in a roughly circular formation in order to analyse the signals emanating from the nearby geothermal energy source. By coincidence these stations are close $(<4 \mathrm{~km})$ to the accelerometric station Ecole Pigeon (PIGA) operated by the Observatoire Volcanologique et Sismologique de Guadeloupe (Institut de Physique du Globe de Paris, IPGP), which is part of the Réseau Accélérometrique Permanent (RAP) of France. In particular, the broadband station LB6 is less than $1 \mathrm{~km}$ from Ecole Pigeon. Records from these stations provide, due to their proximity and lower noise levels, an independent test of the processed displacements deduced from the accelerograms recorded at Ecole Pigeon.

Records from the broadband network have been instrument corrected and then converted to acceleration from velocity through time-domain differentiation [19]. In this study, we convert records to displacement through time-domain integration. Due to the sensitivity of the instruments, records are saturated when the ground motion velocity exceeds $0.5 \mathrm{cms}^{-1}$, such as during the Les Saintes mainshock $\left(M_{w} 6.3\right)$, and hence cannot be used. However, smaller ground motions are successfully recorded by the broadband network.

\section{Record processing}

The level of noise present in the broadband and accelerometric records means that some highpass filtering must be undertaken in order to obtain physically realistic displacements. In order to choose the cut-offs of such filters the signal-to-noise ratio of each record (using the pre-event portion of the record as an estimate of the noise) was examined and the location of the cut-offs chosen where this ratio falls below three. High-pass filtering using a fourth-order Butterworth filter was then applied to the acceleration trace after padding the time-history with zeros and then the filtered acceleration was integrated to displacement. The recording 
of longer pre-event portions by accelerometers would help estimate the cut-off frequencies required for high-pass filtering of these data.

Boore \& Bommer [11] note that this procedure neglects the signal-generated noise. Therefore some of the processed displacements presented here could still contain some long-period noise due to cut-off frequencies that are too small. However, when processing the records presented in this article, the displacements were also examined and the cut-offs varied if the displacements still seemed to be affected by noise. Noise was assumed to still be affecting the displacements if the filtered waveform contained long-period oscillations along the entire length of the record or other unphysical variations such as large displacements at the start or end of the time-history. As shown below, the displacements obtained through this processing procedure show similar features at adjacent stations (Figures 1 and 2) suggesting, following the reasoning of Hanks [26], that the obtained displacements are a good representation of the ground motions. The same processing procedure followed here was used by Ambraseys et al. [3] to process accelerograms from Europe and the Middle East. Akkar \& Bommer [2] independently reprocessed these Eurasian records using a slightly different technique and found that, in general, many of the records in Ambraseys et al. [3] were too severely filtered (shown by recovered peak ground velocities that are too low). This observation suggests that the records presented here are also possibly slightly too severely filtered and that some of the signal has been removed as opposed to not being sufficiently filtered.

Since the subject of this article are long-period motions, accelerometric records from stations of the BRGM accelerometric network of Guadeloupe [e.g. 19] equipped with 12-bit instruments were discarded since they do not have sufficiently high resolution to allow accurate computation of displacements. Table I lists the records examined in this article with the cut-off frequencies 
used. Generally, the records from the broadband stations required a cut-off frequency of $0.03 \mathrm{~Hz}$ while the higher noise levels in the accelerometer records obliged the use of cut-offs less than $0.1 \mathrm{~Hz}$. As broadband records are less noisy than those from accelerometers and since they record continuously, we analysed the influence of the choice of cut-off frequency on accelerometric data using the broadband signal as a reference, for two stations (LB6 and PIGA) about $1 \mathrm{~km}$ apart. For the record from PIGA it is found that there is noise at frequencies less than $0.08 \mathrm{~Hz}$ but, in fact, there is little energy in the broadband record at frequencies less than $0.06 \mathrm{~Hz}$ therefore little signal is lost by filtering at $0.08 \mathrm{~Hz}$. Only records with a filter cut-off frequency of not greater than $0.1 \mathrm{~Hz}$ were retained for analysis.

[Table 1 about here.]

Figure 1 displays comparisons between the displacements recorded at the broadband stations and at the adjacent RAP accelerometric station Ecole Pigeon for the three aftershocks. These figures show that the displacements are similar in form and amplitude. These close correlations between motions observed at adjacent stations recorded by different types of instrument shows that these processed displacements are a good estimate of the ground displacements that occurred at these locations.

[Figure 1 about here.]

\section{Observed displacements}

The processed displacements displayed in Figure 1 are dominated by cycles of displacement with periods of $5-10 \mathrm{~s}$, which is a period much longer than normally would be considered dominant within ground displacements from earthquakes of $M_{w} \approx 5$ at such distances. These 
long-period pulses are similar in form to those observed by Boore et al. [12] for the 1999 Hector Mine earthquake $\left(M_{w} 7.1\right)$, Boore [9] for the 2002 Denali earthquake $\left(M_{w} 7.9\right)$ and Wang et al. [35] for the 2003 San Simeon earthquake $\left(M_{w} 6.5\right)$.

Hanks [26] confirmed the validity of the processed displacement traces of the 1971 San Fernando earthquake he obtained by showing that the displacements were similar at adjacent stations. Since displacements are controlled by the long-period energy content of the ground motions, they are less affected by surface site effects and also are more coherent than accelerations hence it is expected that displacements should be similar over a range of a few kilometres.

Figure 2 shows that the processed displacements recorded at stations on Guadeloupe for the three aftershocks display similar features and are highly coherent especially at rock sites. These similarities, across more than $50 \mathrm{~km}$, further demonstrates that the processed displacements are good representations of the ground displacements.

[Figure 2 about here.]

\section{Elastic displacement response spectra}

Due to the current trend towards displacement-based design, many standard elastic response spectra recently proposed have been developed with a view to providing realistic long-period spectral displacements (SDs). The displacement spectra used within HAZUS [21] and the ASCE 7-05 standard [17] feature an increase in SDs until a magnitude-dependent period at which a SD plateau begins. The period at which this constant SD plateau ends is not given. The SDs of the HAZUS spectrum reach a plateau at a period $T$ given by [21]: $T=10^{\left(M_{w}-5\right) / 2}$, 
which was adopted from the study of [30] on the corner frequency of theoretical source spectra. For $M_{w} 4.9$ and $M_{w} 5.3$ this gives periods of 0.9 and $1.4 \mathrm{~s}$ respectively. Similarly the ASCE 705 standard uses the formula [17]: $T_{c}=10^{0.3 M_{w}-1.25}$ to define the period at which the SDs become constant. For $M_{w} 4.9$ and 5.3 this gives $T_{c}=1.7$ and $2.2 \mathrm{~s}$, respectively, although the smallest magnitude considered by Crouse et al. [17] is $M_{w} 6.0$. On the other hand, the Type 1 (for high seismicity zones, like Guadeloupe) design spectra of Eurocode 8 [16, Annex A] uses a more complicated displacement spectral shape where the SDs increase until a plateau starting at $2 \mathrm{~s}$ and ending at $6 \mathrm{~s}$ and then they decrease until they equal peak ground displacement (PGD) at a period of $10 \mathrm{~s}$. Malhotra [32] has recently proposed a method to construct smooth design spectra based on the well-established method of Newmark \& Hall [33]. In this method the ratio PGD/PGV (whose use in this context was first proposed by Bommer et al. [8]) is used to define the periods at which the plateau in the displacement spectrum begins and ends and also the period at which SD becomes equal to PGD.

Note that these design spectra are generalizations for engineering purposes that seek to capture the main features of observed spectra. An exact match between these standardized shapes and spectra from records should not be expected.

The calculated elastic displacement spectra for $5 \%$ damping for all considered records for the three aftershocks are displayed in Figures 3 to 5. Also shown are displacement spectra predicted using Eurocode 8 normalised to the observed SD at $15 \mathrm{~s}$ (where observed SDs for the examined records approach PGD), in order to more easily compare the shape of the spectra, and the smooth displacement spectra constructed using the method of Malhotra [32]. The spectra from the HAZUS and ASCE 7-05 methodologies are not displayed on the figures due to a lack of space. However, as stated above the SD plateaus of these spectra begin at a 
magnitude-dependent period, which is indicated in the caption of the figures for both the HAZUS and ASCE 7-05 spectra.

These figures show that most of the spectra feature peaks between 5 and $10 \mathrm{~s}$ and the observed SDs do not become equal to PGD until, at least, $10 \mathrm{~s}$. The highpass filtering could have affected the spectral displacements at periods greater than about $8 \mathrm{~s}$ [1] for records filtered at cut-offs of $0.1 \mathrm{~Hz}$. For some records (e.g. the spectra from GFEA) the long-period peak is not clearly present, which could be due to long-period site effects since some stations are located on soft soil where large site amplifications occur [e.g. 19]. The comparisons between the observed and design spectra demonstrate that the form of the observed spectra is not well modelled by recent proposals. The predominant localized peak means that SDs at periods between 5 and $10 \mathrm{~s}$ are underestimated since they are much higher than PGD and they fall outside the location of the expected plateau in the displacement spectrum.

[Figure 3 about here.]

[Figure 4 about here.]

[Figure 5 about here.]

\section{Discussion}

The prominent period of the observed ground displacements during the three studied aftershocks is $5-10 \mathrm{~s}$, which is much greater than would commonly be expected from earthquakes of moderate magnitudes such as these. As mentioned in the introduction, this observation is interesting from seismological and engineering viewpoints. 


\subsection{Seismological viewpoint}

The occurrence of long-period motions at widely-separated stations with different azimuths and site conditions suggests that they are a source, rather than a path or site, effect. Unlike displacements associated with surface waves generated by local site conditions (e.g. basins) that occur in the coda of the record after the high amplitude acceleration, these observed displacements occur within the body-wave portion of the records.

Processes that generate unexpectedly long-period motions have been reported in several locations, such as, volcanoes and hydrothermal systems, e.g.: Aso volcano, Japan [31]; Galeras volcano, Colombia [25]; Popocatepetl volcano, Mexico [4]; and at greater depths beneath these volcanoes [e.g. 27, 34]. In these small systems, the existence of long- (0.2 to $5 \mathrm{~s})$ and very longperiod $(>5 \mathrm{~s})$ motions is explained by the interaction between fluids and solid rock $[15,22,28]$.

The possible response of the hydrothermal system at Bouillante is not responsible for the recorded signals because of the occurrence of long-period motions at locations far from Bouillante. Other crustal earthquakes of similar size recorded at the same stations do not feature such long-period oscillations, such as the earthquake on 23rd March $2006\left(M_{D} 3.7\right)$ at Le Moule (see Figure 2), a similar distance as the Les Saintes aftershocks but at a slightly deeper depth (24 km compared with depths of 5-20 km for Les Saintes events). This observation suggests that the aftershock sequence at Les Saintes has a specific behaviour with respect to the generation of long-period motions.

From the above observations, we suggest that the generation mechanism of the long-period motions observed on Guadeloupe in the Les Saintes sequence may involve the presence of fluids within the source. Guadeloupe belongs to a subduction volcanic arc, where ancient and active volcanoes exist [e.g. 23]. However, the Les Saintes sequence was related to a crustal 
fault system; they were not subduction events. Aftershocks occurred for more than one year $[6,5]$, which is not uncommon for such earthquake swarms. A preliminary analysis of smaller aftershocks of magnitude about 4 recorded at the broadband network reveal that long-period motions were also observed during these events, albeit less clearly.

These observations can be linked with results of source models [e.g. 14] where the fault model involves the lubrication of the fault using an elevated fluid pressure in a thin film of viscous fluid that is sheared between nearly parallel surfaces. This model predicts that lubrication by fluids should decrease the amplitude of frequencies above $1 \mathrm{~Hz}$. Analysis of strong-motion spectra suggest that, in general, ground-motions recorded on Guadeloupe and Martinique seem to be weaker than predicted by empirical ground-motions models derived using data from other regions [19]. The existence of fluid could, therefore, help explain why observed high-frequency $(>1 \mathrm{~Hz})$ ground motions are damped whilst, as shown in this article, the long-period motions are larger than expected.

In addition, long-period motions are not observed on all records of the aftershock sequence. Ground motions of this sequence recorded at Bouillante of aftershocks of similar size some weeks after the main shock exhibit long-period motions, whereas these motions are not observed for late aftershocks. Based on these observations, we speculate that the observed long-period oscillations are due to a temporary source effect (such as the presence of fluids within the source) that vanished some months after the mainshock.

\subsection{Engineering implications}

The observations reported in this article could have engineering implications for the design of structures, such as long bridges and tall buildings, where spectral displacements at periods 
greater than $5 \mathrm{~s}$ are used in the design process. Due to the small size of the aftershocks studied here $\left(M_{w} \approx 5\right)$ and the relatively large source-to-site distances the observed SDs are all less than $2 \mathrm{~mm}$, which is likely to be much too small to cause damage to structures. However, the importance of these observations lies in the possibility that the mechanism responsible for their creation (possibly fluids within the source) could occur during larger earthquakes thus leading to long-period SDs that are much larger than designed against based on seismic building codes, such as Eurocode 8 or ASCE 7-05.

Figure 3 of Faccioli et al. [20] presents average near-field and intermediate-field displacement spectra derived from digital records of the Kobe earthquake. Like many of the displacement spectra shown here, their average spectrum from intermediate-field records also features a plateau at periods from 5 to $10 \mathrm{~s}$ whereas their near-field spectrum shows a plateau at a shorter period. In addition, the recent studies cited above that have also found large-amplitude displacement cycles $[12,9,35]$ have observed them mainly at stations quite distant from the source. Although for all earthquakes examined there is little or no near-source ground-motion data for which to check for such long-period motions. Consequently the unusual form of the displacement spectra shown in Figures 3 to 5 could be a phenomenon that only occurs at source-to-site distances of greater than about $30 \mathrm{~km}$ since at closer distances higher amplitude short-period effects could mask the long-period motions. If this is true then it is unlikely to be too important for the definition of design spectra since ground motions at greater than $30 \mathrm{~km}$ will be too small to cause much damage except during large earthquakes.

To model the displacement spectra presented in Figures 3 to 5 so that the SDs at all periods are well predicted, the form of the Eurocode 8 and the Malhotra [32] spectra could be retained but the periods that control the start and end of the displacement plateau and where SD 
becomes equal to PGD $\left(T_{D}, T_{E}\right.$ and $T_{F}$ in Eurocode 8 and $T_{4}, T_{5}$ and $T_{6}$ in the method of Malhotra [32]) need to be increased to roughly 4,8 and to greater than $10 \mathrm{~s}$, respectively. This will widen the plateau in order to encompass the localized peak. Bommer \& Pinho [7] recently suggested that the control periods in Eurocode 8 may need to be lengthened to correctly specify SDs from large magnitude earthquakes. The more simplified form of the displacement spectrum proposed in HAZUS and ASCE 7-05, which is flat above a certain period, cannot be easily modified to account for the observed localized peak. In order to envelope the observed longperiod peak in the spectra, SDs would have to increase up until roughly $5 \mathrm{~s}$ and then become equal to PGD multiplied by a factor between 2 and 3 (for $5 \%$ damping). The displacement spectra derived by this method, however, would not tend to PGD at long periods, which it must do according to the definition of response spectral displacements. In addition, the SDs for periods longer than about $10 \mathrm{~s}$ would be significantly overestimated.

The limited number of observations presented in this article and those in the previously cited studies means that it is too early to definitively conclude that the long-period SDs predicted by recent design spectra need to be modified. Additional studies based on data recorded by highquality digital accelerograms and/or broadband seismograms need to be conducted to examine how common the large-amplitude long-period displacements that occurred during recent earthquakes are. If it is found that such ground motions frequently occur then modifications of design spectra should be made. There is, however, no reason for the pulses to occur at similar periods. Resonance frequencies of fluid-filled containers depend on physical properties of both fluid and surrounding rock and the geometry of the container $[22,28]$. Therefore a systematic analysis of the source mechanism is required before making any detailed recommendations on required modifications to design spectra to incorporate these effects. 


\section{Conclusion}

In this article, records of three aftershocks of a moderate-size earthquake recorded on two independent networks of instruments were analysed. The data from accelerometers were integrated twice after high-pass filtering to obtain displacements and the data from broadband velocity seismometers were integrated once after instrument correction and filtering to yield displacements. By doing so, we show that the displacements are similar in form and amplitude even for stations located more than few kilometers apart. For larger earthquakes the broadband instruments are saturated and hence cannot be reliably used.

It is found that the prominent periods of ground motions are larger than expected for this size of earthquake, suggesting that long-period motions may be more common for moderate earthquakes than previously thought. A possible cause of these long-period motions is mechanical interaction between rock and fluids at the source. The dynamic interaction between fluids and solids is able to generate long-period waves due to the resonance of small structures $[22,15,28]$. If such long-period motions prove to be observed during other earthquakes then it may be necessary to modify the form of the long-period spectra specified in seismic building codes since they are shown here to poorly model the form of the observed displacement spectra. However, this phenomenon may occur rarely as few observations implying engineering consequence have been observed to date. The unusual form of the displacement spectra observed could be a phenomenon that only occurs at source-to-site distances of greater than about $30 \mathrm{~km}$ since at closer distances higher amplitude short-period effects could mask the longperiod motions. If this is true then it is unlikely to be of major importance for the definition of design spectra since ground motions at greater than $30 \mathrm{~km}$ will be too small to cause much damage except during large earthquakes. 
These results also demonstrate that a comprehensive study of strong ground motion should include co-locating accelerometers to record strong motions and broad-band seismometers for the study of aftershocks and to verify the displacement time-histories derived through double integration of accelerograms. Co-locating accelerographs and high-sampling-rate GPS instruments [35] can also provide joint validation of the long-period displacements observed during earthquakes.

\section{Acknowledgements}

This study was funded by BRGM research and public service projects. We thank Geothermie Bouillante for permitting us to locate some of the broadband stations on their land. The strong-motion networks on Guadeloupe are operated by BRGM and the Institut de Physique du Globe de Paris (IPGP), which is under the aegis of the Réseau Accélérometrique Permanent (RAP) of France. The RAP data centre is based at Laboratoire de Géophysique Interne et de Tectonophysique, Grenoble. We are very grateful to the personnel of these organisations for operating the stations and providing us with the data, without which this study would have been impossible. We thank Julian Bommer and Sinan Akkar for their pertinent comments on earlier drafts, which led to significant improvements to the article. Figures 1 and 2 were drawn using GMT [36].

references

[1] Akkar, S., \& Bommer, J. J. 2006. Influence of long-period filter cut-off on elastic spectral displacements. Earthquake Engineering and Structural Dynamics, 35(9), 1145-1165. 
[2] Akkar, S., \& Bommer, J. J. 2007. Empirical prediction equations for peak ground velocity derived from strong-motion records from Europe and the Middle East. Bulletin of the Seismological Society of America. In press.

[3] Ambraseys, N. N., Douglas, J., Sigbjörnsson, R., Berge-Thierry, C., Suhadolc, P., Costa, G., \& Smit, P. M. 2004 (Feb). Dissemination of European Strong-Motion Data, vol. 2 using Strong-Motion Datascape Navigator. CD-ROM collection. Engineering and Physical Sciences Research Council, United Kingdom.

[4] Arciniega-Ceballos, A., Chouet, B., \& Dawson, P. 2003. Long-period event and tremor at Popocateptl volcano (1994-2000) and their broadband characteristics. Bulletin volcanologique, 65, 124-135.

[5] Beauducel, F., et al. . 2006 (May). Le séisme des Saintes du 21 décembre 2004 (Guadeloupe, $\left.M_{w}=6.3\right)$ et sa séquence de 27000 répliques. In: IIIème Journées techniques et scientifiques $d u R A P$. In French.

[6] Bertil, D., Bazin, S., Mallarino, D., \& Beauducel, F. 2005. Localisation des principales répliques du séisme des Saintes du 21 novembre 2004. Tech. rept. Centre de Données Sismologique des Antilles.

[7] Bommer, J. J., \& Pinho, R. 2006. Adapting earthquake actions in Eurocode 8 for performance-based seismic design. Earthquake Engineering and Structural Dynamics, 35(1), 39-55. DOI: $10.1002 /$ eqe.530.

[8] Bommer, J. J., Elnashai, A. S., \& Weir, A. G. 2000. Compatible acceleration and displacement spectra for seismic design codes. In: Proceedings of Twelfth World Conference on Earthquake Engineering. Paper no. 207. 
[9] Boore, D. M. 2004a. Ground motion in Anchorage, Alaska, from the 2002 Denali fault earthquake: Site response and displacement pulses. Bulletin of the Seismological Society of America, 94(6B), S72-S84.

[10] Boore, D. M. 2004b. Long-period ground motions from digital acceleration recordings: A new era in engineering seismology. In: Proceedings of the International Workshop on Future Directions in Instrumentation for Strong Motion and Engineering Seismology. Kusadasi, Turkey: Kluwer.

[11] Boore, D. M., \& Bommer, J. J. 2005. Processing of strong-motion accelerograms: Needs, options and consequences. Soil Dynamics and Earthquake Engineering, 25(2), 93-115.

[12] Boore, D. M., Stephens, C. D., \& Joyner, W. B. 2002. Comments on baseline correction of digital strong-motion data: Examples from the 1999 Hector Mine, California, earthquake. Bulletin of the Seismological Society of America, 92(4), 1543-1560.

[13] Bragato, P. L., \& Slejko, D. 2005. Empirical ground-motion attenuation relations for the eastern Alps in the magnitude range 2.5-6.3. Bulletin of the Seismological Society of America, 95(1), 252-276. doi: 10.1785/0120030231.

[14] Brodsky, E. E., \& Kanamori, H. 2001. Elastohydrodynamic lubrication of faults. Journal of Geophysical Research, 106(B8), 16357-16374.

[15] Chouet, B. 1986. Dynamics of a fluid-driven crack in three dimensions by the finite difference method. Journal of Geophysical Research, 91, 13967-13992.

[16] Comité Européen de Normalisation (CEN). 2005 (Sep). Eurocode 8, Design of structures 
for earthquake resistance — part 1: General rules, seismic actions and rules for buildings. European Standard NF EN 1998-1.

[17] Crouse, C. B., Leyendecker, E. V., Somerville, P. G., Power, M., \& Silva, W. J. 2006 (Apr). Development of seismic ground-motion criteria for the ASCE 7 standard. In: Proceedings of the Eighth U.S. National Conference on Earthquake Engineering. Paper no. 533.

[18] Dahle, A., Bungum, H., \& Kvamme, L. B. 1990. Attenuation models inferred from intraplate earthquake recordings. Earthquake Engineering and Structural Dynamics, 19(8), $1125-1141$.

[19] Douglas, J., Bertil, D., Roullé, A., Dominique, P., \& Jousset, P. 2006. A preliminary investigation of strong-motion data from the French Antilles. Journal of Seismology, 10(3), 271-299.

[20] Faccioli, F., Paolucci, R., \& Rey, J. 2004. Displacement spectra for long periods. Earthquake Spectra, 20(2), 347-376.

[21] FEMA. 2003. HAZUS-MH. Technical manual. Federal Emergency Management Agency, Washington DC.

[22] Ferrazzini, V., \& Aki, K. 1987. Slow waves trapped in fluid-filled infinite-crack: Implication for volcanic tremor. Journal of Geophysical Research, 92(B9), 9215-9223.

[23] Feuillet, N. 2000. Sismotectonique des Petites Antilles. Ph.D. thesis, University of Paris VII.

[24] Frisenda, M., Massa, M., Spallarossa, D., Ferretti, G., \& Eva, C. 2005. Attenuation 
relationships for low magnitude earthquakes using standard seismometric records. Journal of Earthquake Engineering, 9(1), 23-40.

[25] Gil Cruz, F., \& Chouet, B. A. 1997. Long-period events, the most characteristic seismicity accompanying the emplacement and extrusion of a lava dome in Galeras Volcano, Colombia, 1991. Journal of Volcanology and Geothermal Research, 77, 121-158.

[26] Hanks, T. C. 1975. Strong ground motion of the San Fernando, California, earthquake: Ground displacements. Bulletin of the Seismological Society of America, 65(1), 193-225.

[27] Hasegawa, A., \& Yamamoto, A. 1994. Deep, low-frequency microearthquakes in or around seismic low-velocity zones beneath active volcanoes in northeastern Japan. Tectonophysics, 233, $233-252$.

[28] Jousset, P., Neuberg, J., \& Sturton, S. 2003. Modelling the time-dependent frequency content of low-frequency volcanic earthquakes. Journal of Volcanology and Geothermal Research, 128, 201-223.

[29] Jousset, P., Bès de Berc, S., Fabriol, H., \& Chouet, B. 2004. Monitoring and exploration of geothermal fields using broadband seismology: Application to Bouillante, Guadeloupe. In: IAVCEI General Assembly, Pucon, Chile, 14th-19th November. Symposium 8. 508b-pf-126. Abstract only.

[30] Joyner, W. B., \& Boore, D. M. 1988. Measurement, characterization, and prediction of strong ground motion. Pages 43-102 of: Proceedings of Earthquake Engineering 83 Soil Dynamics II. Geotechnical Division, ASCE. 
[31] Kubotera, A. 1974. Volcanic tremors at Aso volcano. Pages 29-47 of: Civetta, L., Gasparini, P., Luongo, G., \& Rapolla, A. (eds), Physical volcanology. Elsevier, Netherlands.

[32] Malhotra, P. K. 2006. Smooth spectra of horizontal and vertical ground motions. Bulletin of the Seismological Society of America, 96(2), 506-518. doi: 10.1785/0120050062.

[33] Newmark, N. M., \& Hall, W. J. 1982. Earthquake Spectra and Design. Berkeley, USA: Earthquake Engineering Research Institute.

[34] Power, J. A., Stihler, S. D., White, R. A., \& Moran, S. C. 2004. Observations of deep long-period (DLP) seismic events beneath Aleutian arc volcanoes: 1989-2002. Journal of Volcanology and Geothermal Research, 138(3-4), 243-266.

[35] Wang, G.-Q., Boore, D. M., Tang, G., \& Zhou, X. 2007. Comparisons of ground motions from collocated and closely-spaced 1-sample-per-second Global Positioning System (GPS) and accelerograph recordings of the 2003, M6.5 San Simeon, California, earthquake in the Parkfield Region. Bulletin of the Seismological Society of America. In press.

[36] Wessel, P., \& Smith, W. H. F. 1998. New, improved version of the Generic Mapping Tools released. EOS Transactions $A G U, \mathbf{7 9}, 579$.

[37] Yu, Y., \& Hu, Y. 2004. Empirical long-period response spectral attenuation relations based on southern California digital broad-band recordings. In: Proceedings of Thirteenth World Conference on Earthquake Engineering. Paper no. 0344.

[38] Zahradník, J. 2004. How many seismographs do we need to record ground motion at a station? Studia Geophysica et Geodaetica, 48, 483-492. 
1 Ground displacements of the three aftershocks recorded at LB2, LB3, LB6 and Ecole Pigeon (PIGA). NS component of LB2 was not working correctly at the time of earthquakes and LB3 and LB6 were not working correctly at the time of the third aftershock. . . . . . . . . . . . . . . .

List of Figures

2 Observed ground displacements for the three studied aftershocks. On the map, filled symbols are rock sites, unfilled symbols are soft soil sites, triangles are broadband stations and squares are accelerometric stations (see Table I for details). The black star indicates the location (Observatoire Volcanologique et Sismologique de Guadeloupe) of the Le Moule earthquake $\left(M_{D} 3.7\right)$. . . . . .

3 Observed elastic displacement response spectra (black lines) for records from the 21st November 2004 13:37 $\left(M_{w} 5.3\right)$ aftershock, predicted Eurocode 8 spectra (light grey lines) normalised to observed SD at $15 \mathrm{~s}$ (at $4 \mathrm{~s}$ for vertical spectra since SDs are not defined for longer periods in EC8) and predicted spectra using procedure of Malhotra [32] (dark grey lines). The SD plateaus in the HAZUS and ASCE 7-05 spectra begin at 1.4 and $2.2 \mathrm{~s}$, respectively. Also given are the station codes, epicentral distances and Eurocode 8 site classes. Lines for the observed spectra are thick for periods less than the conservative criteria given by Akkar \& Bommer [1] as to when the SDs are not affected by filtering, thinner for periods between their conservative and tolerant criteria and thin for longer

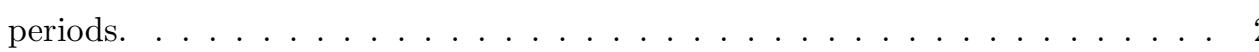


$4 \quad$ Like Figure 3 but for records from the 27th November 2004 23:44 $\left(M_{w} 4.9\right)$ aftershock. The SD plateaus in the HAZUS and ASCE 7-05 spectra begin at

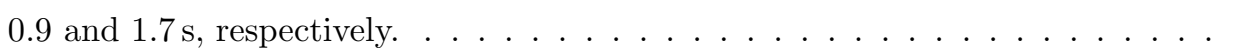

$5 \quad$ Like Figure 3 but for records from the 2nd December 2004 14:47 $\left(M_{w} 5.0\right)$ aftershock. The SD plateaus in the HAZUS and ASCE 7-05 spectra begin at

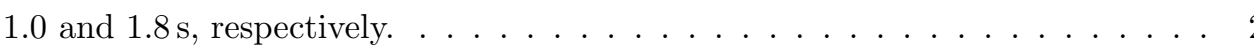




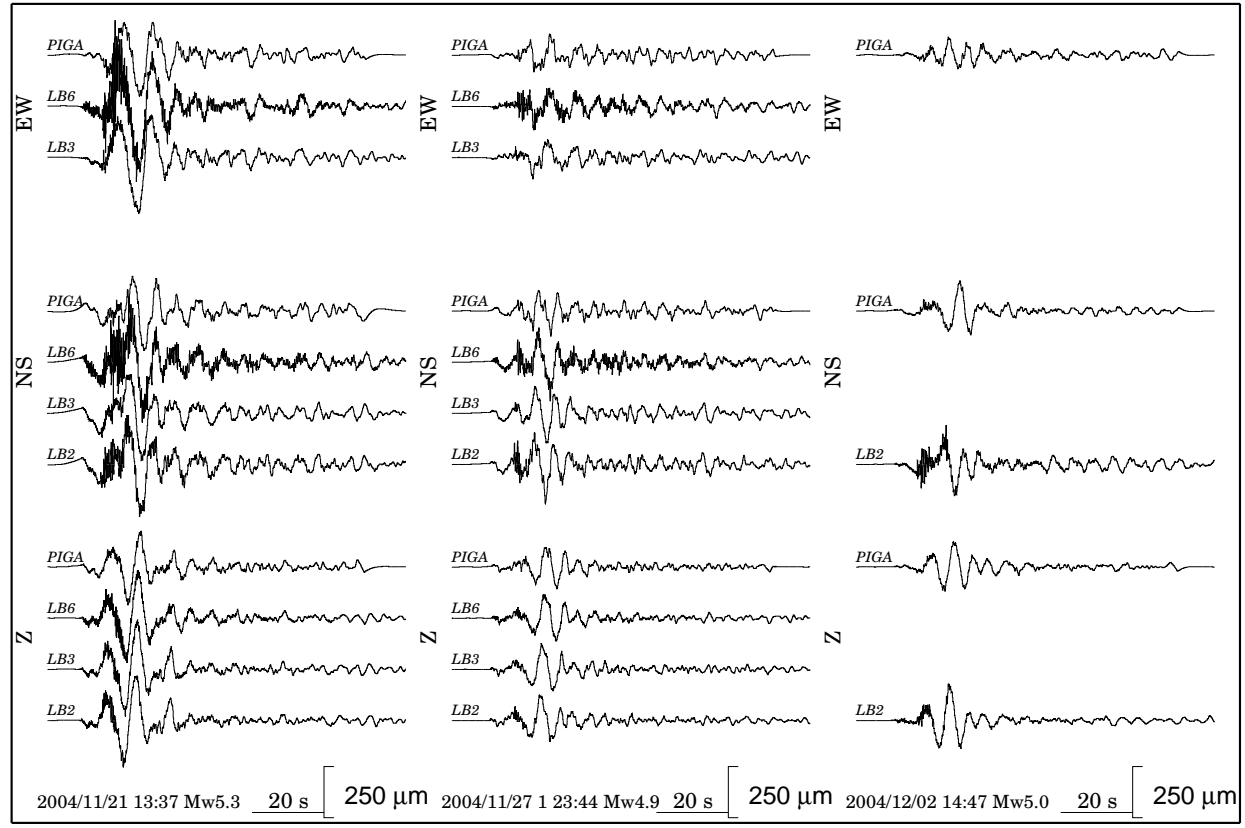

Figure 1. Ground displacements of the three aftershocks recorded at LB2, LB3, LB6 and Ecole Pigeon (PIGA). NS component of LB2 was not working correctly at the time of earthquakes and LB3 and LB6 were not working correctly at the time of the third aftershock. 

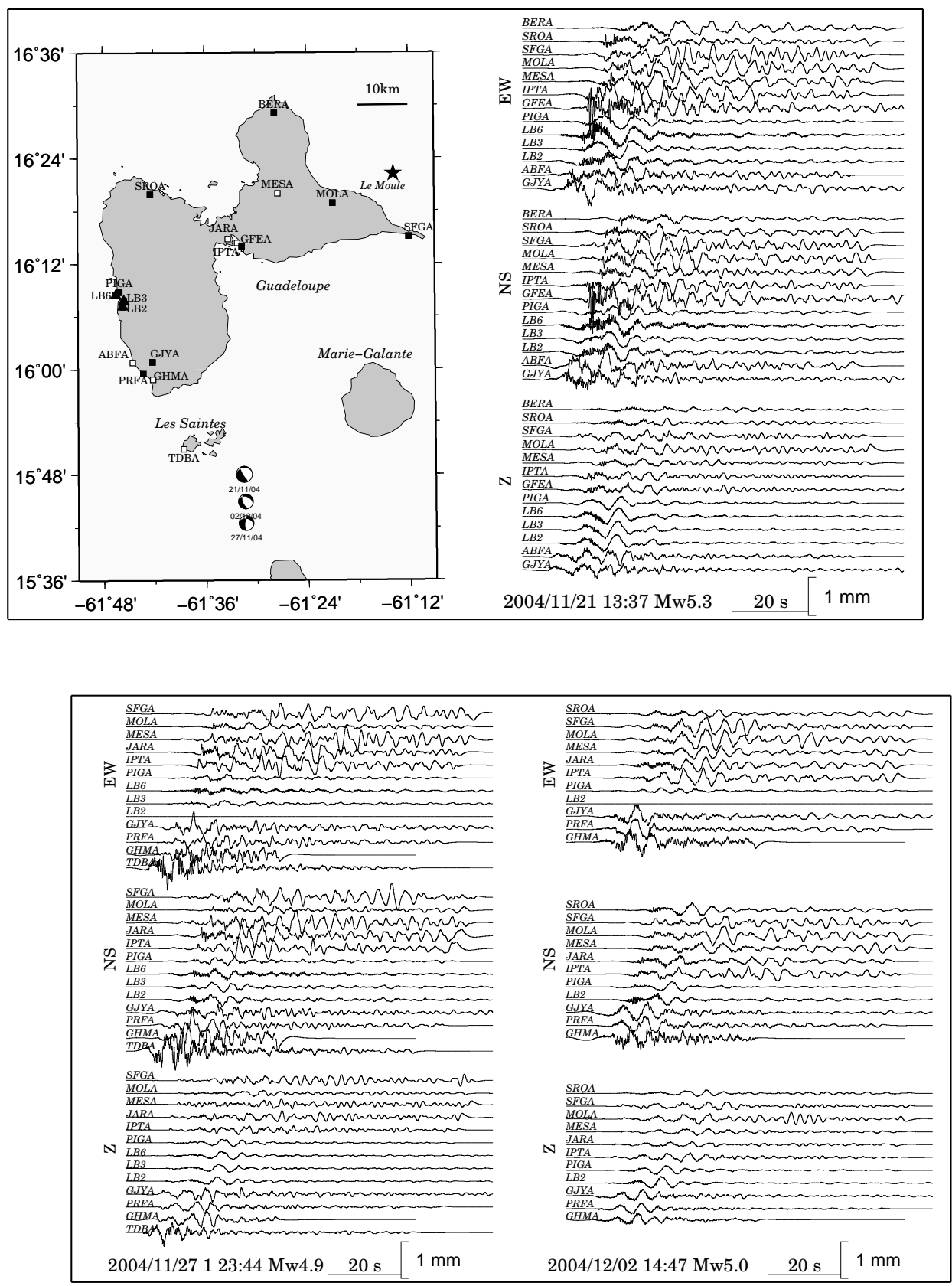

Figure 2. Observed ground displacements for the three studied aftershocks. On the map, filled symbols are rock sites, unfilled symbols are soft soil sites, triangles are broadband stations and squares are accelerometric stations (see Table I for details). The black star indicates the location (Observatoire Volcanologique et Sismologique de Guadeloupe) of the Le Moule earthquake $\left(M_{D} 3.7\right)$. 


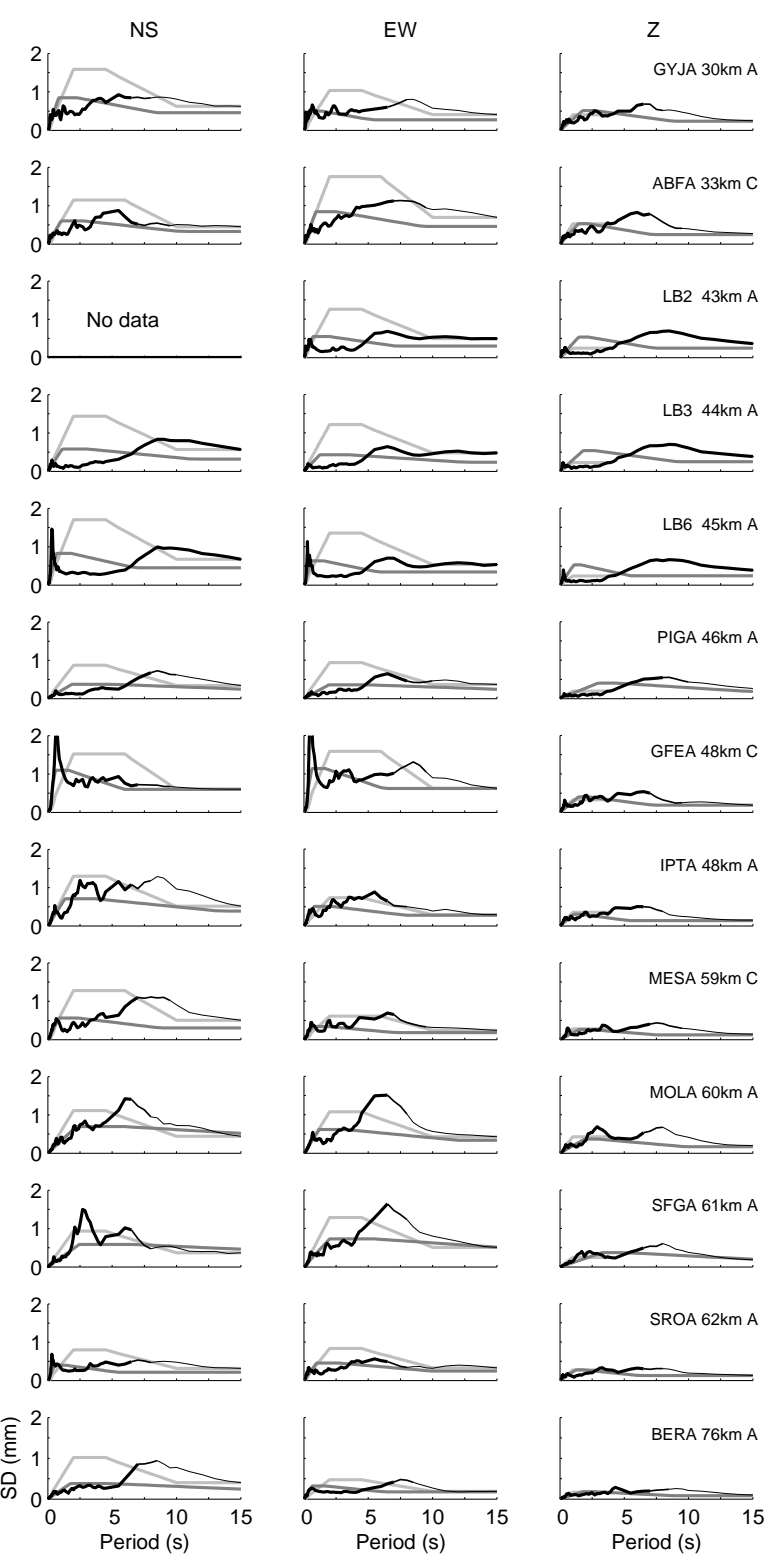

Figure 3. Observed elastic displacement response spectra (black lines) for records from the 21st November 2004 13:37 $\left(M_{w} 5.3\right)$ aftershock, predicted Eurocode 8 spectra (light grey lines) normalised to observed SD at $15 \mathrm{~s}$ (at $4 \mathrm{~s}$ for vertical spectra since SDs are not defined for longer periods in EC8) and predicted spectra using procedure of Malhotra [32] (dark grey lines). The SD plateaus in the HAZUS and ASCE 7-05 spectra begin at 1.4 and $2.2 \mathrm{~s}$, respectively. Also given are the station codes, epicentral distances and Eurocode 8 site classes. Lines for the observed spectra are thick for periods less than the conservative criteria given by Akkar \& Bommer [1] as to when the SDs are not affected by filtering, thinner for periods between their conservative and tolerant criteria and thin for longer periods. 


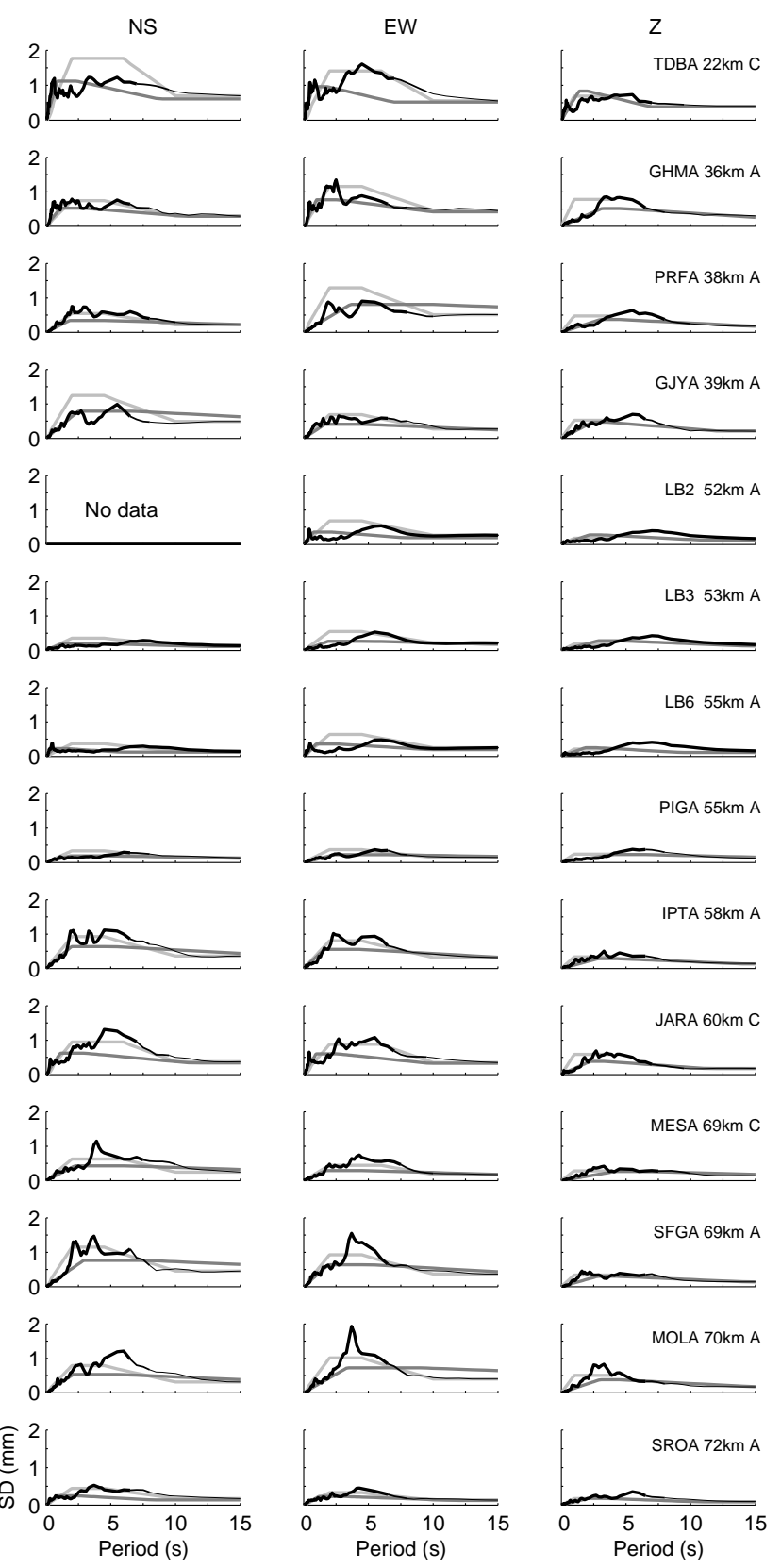

Figure 4. Like Figure 3 but for records from the 27th November 2004 23:44 $\left(M_{w} 4.9\right)$ aftershock. The SD plateaus in the HAZUS and ASCE 7-05 spectra begin at 0.9 and $1.7 \mathrm{~s}$, respectively. 


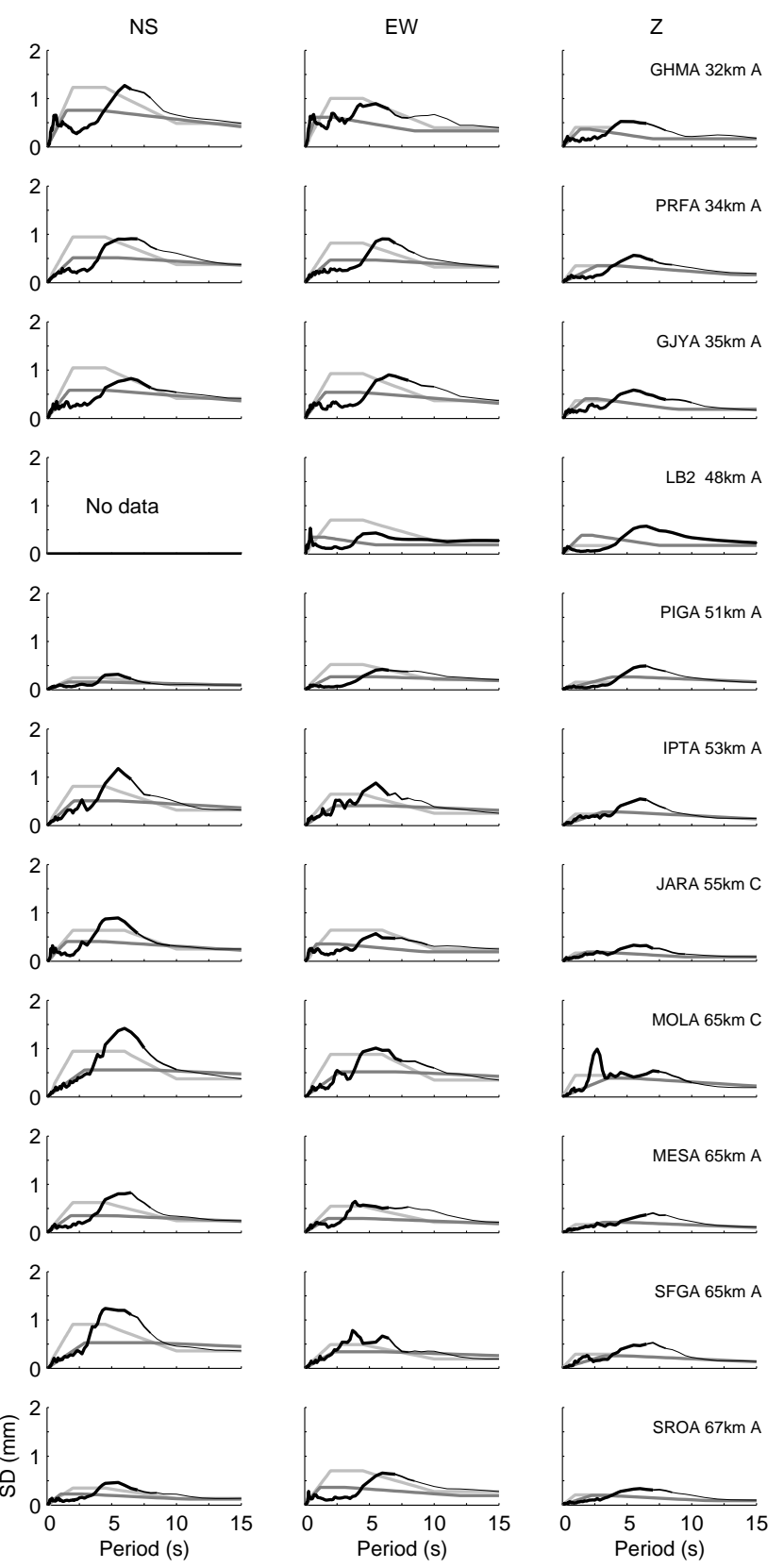

Figure 5. Like Figure 3 but for records from the 2nd December 2004 14:47 $\left(M_{w} 5.0\right)$ aftershock. The SD plateaus in the HAZUS and ASCE 7-05 spectra begin at 1.0 and $1.8 \mathrm{~s}$, respectively. 


\section{List of Tables}

I Characteristics of records analysed in this study, where $d_{e}$ is epicentral distance and $f_{l}$ is the cut-off frequency of the high-pass filter used. . . . . . . . . . 30 
Table I. Characteristics of records analysed in this study, where $d_{e}$ is epicentral distance and $f_{l}$ is the cut-off frequency of the high-pass filter used.

\begin{tabular}{|c|c|c|c|c|c|c|c|c|}
\hline \multirow[t]{2}{*}{ Station } & \multirow[t]{2}{*}{ Site class } & \multirow[t]{2}{*}{ Inst. type } & \multicolumn{2}{|c|}{$\begin{array}{c}21 / 11 / 0413: 37 \\
M_{w} 5.3\end{array}$} & \multicolumn{2}{|c|}{$\begin{array}{c}27 / 11 / 0423: 44 \\
M_{w} 4.9\end{array}$} & \multicolumn{2}{|c|}{$\begin{array}{c}02 / 12 / 0414: 47 \\
M_{w} 5.0\end{array}$} \\
\hline & & & $\begin{array}{l}d_{e} \\
(\mathrm{~km})\end{array}$ & $\begin{array}{l}f_{l} \\
(\mathrm{~Hz})\end{array}$ & $\begin{array}{l}d_{e} \\
(\mathrm{~km})\end{array}$ & $\begin{array}{l}f_{l} \\
(\mathrm{~Hz})\end{array}$ & $\begin{array}{l}d_{e} \\
(\mathrm{~km})\end{array}$ & $\begin{array}{l}f_{l} \\
(\mathrm{~Hz})\end{array}$ \\
\hline GJYA & Rock & $\mathrm{K} 2$ & 30 & 0.10 & 39 & 0.10 & 35 & 0.08 \\
\hline ABFA & Soft soil & ES-T & 33 & 0.10 & - & - & - & - \\
\hline LB2 & Rock & CMG-40T & 43 & 0.03 & 52 & 0.03 & 48 & 0.03 \\
\hline LB3 & Rock & CMG-40T & 44 & 0.03 & 53 & 0.03 & - & - \\
\hline LB6 & Rock & CMG-40T & 46 & 0.03 & 55 & 0.03 & - & - \\
\hline PIGA & Rock & ES-T & 46 & 0.08 & 55 & 0.10 & 51 & 0.10 \\
\hline GFEA & Soft soil & K2 & 48 & 0.10 & - & - & - & - \\
\hline IPTA & Rock & ES-T & 48 & 0.10 & 58 & 0.10 & 53 & 0.10 \\
\hline MESA & Soft soil & ES-T & 59 & 0.10 & 69 & 0.09 & 65 & 0.10 \\
\hline MOLA & Rock & ES-T & 60 & 0.10 & 70 & 0.10 & 65 & 0.09 \\
\hline SFGA & Rock & ES-T & 61 & 0.10 & 69 & 0.10 & 65 & 0.10 \\
\hline SROA & Rock & ES-T & 62 & 0.10 & 72 & 0.10 & 67 & 0.09 \\
\hline BERA & Rock & ES-T & 76 & 0.09 & - & - & - & - \\
\hline TDBA & Soft soil & ES-T & - & - & 22 & 0.10 & - & - \\
\hline GHMA & Hill & AC- $23 \mathrm{H}$ & - & - & 36 & 0.10 & 32 & 0.10 \\
\hline PRFA & Rock & ES-T & - & - & 38 & 0.08 & 34 & 0.09 \\
\hline JARA & Soft soil & ES-T & - & - & 60 & 0.10 & 55 & 0.10 \\
\hline
\end{tabular}

